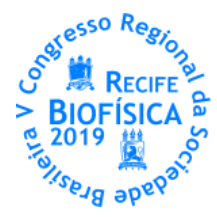

\title{
ATIVIDADE ANTIBACTERIANA DE NANOPRISMAS DE PRATA
}

\author{
Cláudio Henrique Rodrigues ${ }^{1 *}$, Evanísia Assis Góes de Araújo, Thiago Pajeú Nascimento², Adriana Fontes ${ }^{3}$, Juliana \\ de Souza Alencar Falcão ${ }^{4}$, Christiane Philippini Borges ${ }^{5}$ Goreti Carvalho Pereira ${ }^{6}$, Ana Lúcia Figueiredo Porto², Beate \\ Saegesser Santos ${ }^{1}$
}

\begin{abstract}
${ }^{1}$ Departamento de Ciências Farmacêuticas, UFPE; ${ }^{2}$ Departamento de Morfologia e Fisiologia Animal, UFRPE, ${ }^{3}$ Departamento de Biofísica e Radiobiologia, UFPE; ${ }^{4}$ Centro de Educação e Saúde, UFCG; ${ }^{5}$ Departamento de Química, UEPG ${ }^{6}$ Departamento de Química Fundamental, UFPE *claudiohrodrigues@live.com
\end{abstract}

\section{INTRODUÇÃO}

Nanopartículas de prata (AgNPs) são sistemas coloidais que vêm emergindo como uma alternativa ao uso de antibióticos, devido ao fato desses últimos comumente causarem resistência, desencadeando dificuldades na terapia (RAl et al., 2009). No campo da nanotecnologia diversos materiais são comumente utilizados como tratamento alternativo antibacteriano, sendo a nanopartícula de prata bastante efetivo (GONG et al., 2007).

Desde a antiguidade, já se relatam efeitos antimicrobianos da prata, sendo utilizada para controle bacteriano na odontologia, na desinfecção de cateteres e feridas (KIM et. al., 2007). Porém uma nanoestruturação controlada da Ag e de outros metais, como o cobre, pode levar a uma alternativa terapêutica mais eficaz. 0 potencial terapêutico dessas partículas ainda pode ser amplificado por meio da funcionalização de suas superfícies (RUPARELIA et. al., 2008).

Diversas são as metodologias utilizadas para a síntese das AgNPs que podem ser divididas em químicas, físicas e biológicas (IRAVANI et. al., 2014). Os métodos mais utilizados promovem como produto a formação de nanopartículas com boa distribuição de tamanho e mesma região de absorção, de forma a obter um material uniforme (SAADE, 2013). Entre essas metodologias, temos o crescimento de nanopartículas por semente, relatada por Aherne et. al. (2008). Esta metodologia utiliza um polímero aniônico como agente surfactante que ao se fixar a determinadas faces dos pequenos cristais esféricos (denominados sementes), provoca uma anisotropia na superfície, tal que, o crescimento de partículas na forma de nanoprismas é favorecido gerando AgNPs anisotrópicas como produto majoritário da síntese $(>95 \%)$. Essa metodologia envolve a catálise das sementes sintetizadas com o polímero pelo ácido ascórbico, e uma maior adição de íons $\mathrm{Ag}^{+}$, podendo então controlar a forma e o tamanho por meio do controle da quantidade adicionada das sementes no meio reacional.

O poli(4-estirenosulfonato) - PSSS é conhecido por conta de sua preferência a algumas faces das esferas de prata, sendo esse fator, determinante para definir as faces onde haverá crescimento, e também definido por conta do tamanho do polímero, onde maiores conseguem separar melhor essas sementes no meio reacional, e promovem um crescimento mais uniforme. Por ser um método rápido, anisotrópico e simples, essa metodologia é uma grande alternativa para diversas aplicações biomédicas. Os nanoprismas têm também potencial para gerar efeitos plasmônicos mais acentuados pela geometria (MILLSTONE et. al., 2009). Dessa forma o objetivo desse trabalho é avaliar a atividade antibacteriana dos nanoprismas crescidos pela técnica de crescimento a partir de sementes, frente a seis cepas isoladas de bactérias e observar propriedades cinéticas de crescimento para AgNPs utilizando o PSSS de $200 \mathrm{kDa}$.

\section{MATERIAIS E MÉTODOS}

1. Síntese das AgNPs

A metodologia para síntese das AgNPs foi adaptada da proposta por Aherne et. al., (2008). Em um experimento típico, combinou-se $5 \mathrm{~mL}$ de citrato de sódio $\left(5 \mathrm{~mL}, 2,5 \mathrm{mmol} . \mathrm{L}^{-1}\right)$, solução de PSSS $\left(0,25 \mathrm{~mL}, 500 \mathrm{mg} \cdot \mathrm{L}^{-1}, M M\right.$ 200.000) e borohidreto de sódio $\left[\mathrm{NaBH}_{4}\left(0,3 \mathrm{~mL}, 10 \mathrm{mmol} . \mathrm{L}^{-1}\right)\right.$, recém preparada], com posterior adição de nitrato de prata $\left(5 \mathrm{~mL}, 0,5 \mathrm{mmol}^{-1} \mathrm{~L}^{-1}\right)$, gota a gota, resultando em partículas esféricas e uma solução de coloração amarelada. Para o crescimento dessas partículas, utilizou-se as mesmas condições, onde combinou-se água deionizada $(5 \mathrm{~mL})$, ácido ascórbico $\left(75 \mu \mathrm{L}, 10 \mathrm{mmol} . \mathrm{L}^{-1}\right)$ e volumes variados da suspensão contendo as sementes (i.e. 90,200 e $650 \mu \mathrm{L}$ ), seguido pela adição de solução aquosa de $\mathrm{AgNO}_{3}\left(3 \mathrm{~mL}, 0,5 \mathrm{mmol} . \mathrm{L}^{-1}\right)$. Os sistemas foram caracterizados utilizando espectroscopia UV-Vis, com varredura entre 350 e $750 \mathrm{~nm}$.

2. Preparação das AgNPs

Para utilização nesse estudo, as AgNPs foram centrifugadas utilizando-se $12.000 \mathrm{rpm}$ a $4{ }^{\circ} \mathrm{C}$, sendo obtido um precipitado. 0 sobrenadante foi retirado e o precipitado foi redisperso em $500 \mu \mathrm{L}$, obtendo um concentrado, que foi utilizado para o experimento. Também foi analisada a atividade do sobrenadante, para confirmar que não há resíduos tóxicos da síntese no sobrenadante.

3. Obtenção dos microrganismos e preparação dos inóculos Foram testados os microrganismos: Pseudomonas aeruginosa ATCC 27853, Escherichia coli ATCC 25922, Klebsiella pneumoniae ATCC 29665, Staphylococcus aureus ATCC 6538 e Bacillus subtillis ATCC 6633. Eles foram reativados em meio caldo nutriente em estufa bacteriológica a $37^{\circ} \mathrm{C}$ por $24 \mathrm{~h}$, passado esse período foi feita uma suspensão direta das colônias em uma solução de caldo TSB (Tryptic Soy Broth) ajustada para concentração final de $1,0 \times 10^{7} \mathrm{UFC} / \mathrm{mL}$ através de leitura espectrofotométrica de acordo com a NCCLS (2003).

4. Atividade antimicrobiana

A avaliação da atividade antimicrobiana foi realizada em microplacas de 96 poços. Para tanto, $50 \mu \mathrm{L}$ de cada uma das AgNPs foram adicionados a $45 \mu \mathrm{L}$ do meio caldo Müller Hinton juntamente com $5 \mu \mathrm{L}$ da cultura dos microrganismos testes já previamente padronizados. Como controle positivo foi utilizado clorexidina $0,12 \%$, como negativo apenas o meio de cultura e os microrganismos. As microplacas então foram incubadas em estufa a $37{ }^{\circ} \mathrm{C}$ por $24 \mathrm{~h}$, após este período, foram determinadas as 
absorbâncias a $595 \mathrm{~nm}$ por um leitor de microplacas ELISA Immunochem-2100 HTI Medical Inc. Após a análise das absorbâncias em $595 \mathrm{~nm}$, as microplacas foram submetidas ao revelador resazurina $(100 \mu \mathrm{g} / \mathrm{mL})$ do qual $30 \mu \mathrm{L}$ foi adicionado em cada poço dos testes com os microrganismos por $2 \mathrm{~h}$.

\section{RESULTADOS E DISCUSSÃO}

0 perfil espectral observado para os produtos da síntese mostra que temos nos sistemas coloidais predominantemente nanoprismas. $\mathrm{Na}$ Figura 1, podemos ver que, ao alterar o volume de semente utilizado para o crescimento, também há alteração do comprimento de onda, que se relaciona diretamente com o tamanho, uma vez que todas tem a mesma forma induzida pela presença do polímero.

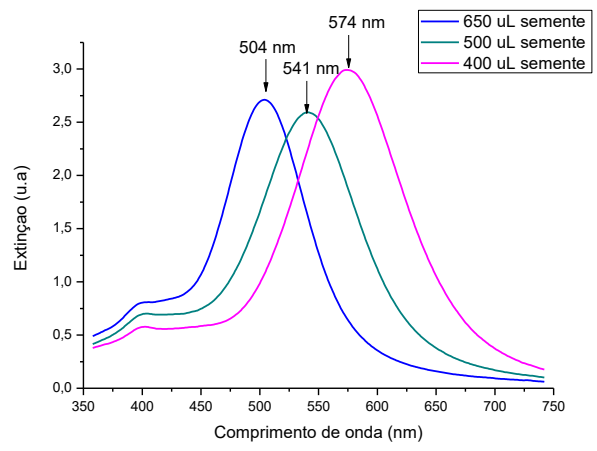

Figura 1. Espectros de extinção observados para a síntese utilizando PSSS 200 kDa.

O tamanho do polímero é de fundamental importância para que se obtenha um produto com maior quantidade de prismas. Quando temos um polímero de maior massa molecular, os núcleos conseguem ficar afastados de forma que os íons $\mathrm{Ag}^{+}$, quando adicionados, consigam se ligar a esse núcleo de forma uniforme, sem que haja aglomeração ou crescimento das sementes de forma esférica. Quando utilizando o polímero de $70 \mathrm{kDa}$, foi possível ver que não houve muito consumo de sementes, ocorrendo também o processo de crescimento esférico, sendo ainda o produto majoritário em alguns volumes de semente (RODRIGUES et. al., 2018). As suspensões de AgNPs foram utilizadas sem diluição, uma vez que há uma grande dificuldade na obtenção de pó e de uma diluição estimada de forma a se ter definida a concentração inibitória média. Os sistemas então, foram padronizados na mesma diluição a partir do precipitado obtido, com a finalidade de se manter uma uniformidade.

Esses resultados já estão mais de acordo com a síntese proposta por Aherne, e utilizada como base, para a qual o polímero utilizado tinha massa molecular de $1.000 \mathrm{kDa}$, e a quantidade de sementes era mínima, tendo realmente uma maior quantidade de nanoprismas. A centrifugação foi realizada para retirar a maior quantidade de interferentes da síntese possível, de modo que tudo aquilo que não reagiu fosse eliminado, e apenas restasse as AgNPs. Esse sobrenadante não desencadeou inativação microbiana, e alguma atividade exercida nos microrganismos se deu por conta da presença das partículas ainda no sobrenadante, e quão menor for o tamanho da partícula, mais difícil é de se obter um precipitado em grande quantidade.

O mecanismo de ação das AgNPs foi explicado por Rai et. al., (2009), que justificou essa alta atividade pelo fato da grande área superficial das nanopartículas, que promovem alguns efeitos na bactéria, como a associação à parede bacteriana e também a penetração na bactéria, sendo esses processos mediados por grupos sulfidrilas, que possuem uma alta interação com a prata. Também são alvos os grupos contendo fósforo do DNA e atacam a cadeia respiratória, liberando íons $\mathrm{Ag}^{+}$. Diversas formas de AgNPs foram estudadas por Morones et. al., (2005), e foi observado que o efeito bactericida está ligado diretamente à estrutura da partícula coloidal. Pal et. al., (2007) evidenciaram que uma menor quantidade de partículas era necessária para se obter uma inativação bacteriana utilizando nanoprismas quando comparados aos sistemas esféricos.

As bactérias gram positivas utilizadas no presente estudo tiverem uma maior sensibilidade corroborando com o estudo realizado por Azam et. al., (2012) que utilizando AgNPs esféricas também teve inibição das bactérias gram negativas. A susceptibilidade das bactérias gram positivas frente às três AgNPs utilizadas pode ser vista na Figura 2, que mostra a morte das bactérias de acordo com as partículas utilizadas. As AgNPs utilizando $200 \mu \mathrm{L}$ da semente promoveram a inibição completa das bactérias gram positivas $B$. subtlis ATCC 6633 e do S. aureus ATCC 6538, entretanto não foi observada inibição completa para a Corynebacterium sp. ATCC 6931, que teve uma viabilidade de $40,6 \%$ após $24 \mathrm{~h}$ de incubação com o sistema coloidal.

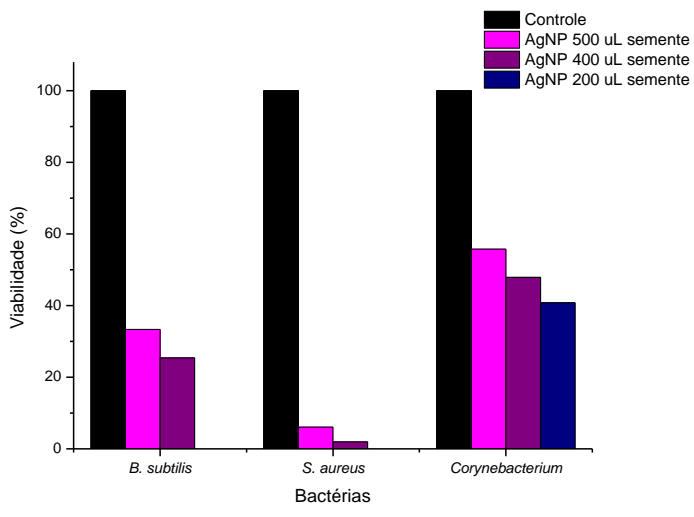

Figura 2. Viabilidade bacteriana observada após $24 \mathrm{~h}$ de experimento para bactérias gram positivas, utilizando AgNPs.

Estudos realizados por RUPARELIA et al., 2008 utilizando nanopartículas esféricas de prata também foram efetivos frente as bactérias $B$. subtlis e do $S$. aureus comprovando assim como os resultados obtidos nesse trabalho a alta sensibilidade dessas bactérias aos coloides de prata. Para as bactérias gram negativas, não foi observado nenhuma inativação completa (Figura 3), uma vez que essas bactérias possuem duas membranas de fosfolipídeos, uma interna e outra externa, o que pode impedir a penetrabilidade da substância (CARVALHO et al, 2016).

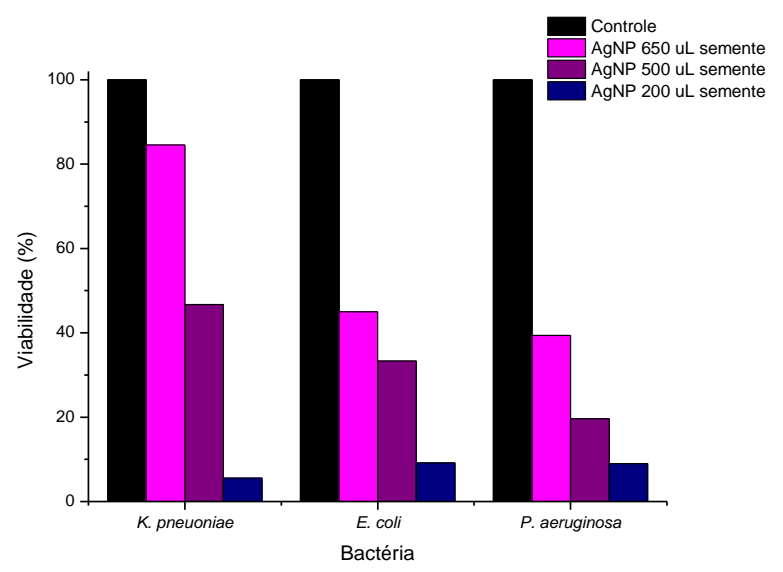

Figura 3. Viabilidade bacteriana observada após $24 \mathrm{~h}$ de experimento para bactérias gram negativas, utilizando AgNPs.

Diferente do que relatado por OUAY et al., 2015 a atividade antimicrobiana foi proporcional ao tamanho da partícula, sendo 
mais efetiva para as maiores. Através do uso da resazurina como revelador foi possível a visualização da atividade antimicrobiana como pode ser observado na Figura 4 , onde a presença da coloração azul representou ausência de crescimento e da cor rosa presença de crescimento bacteriano (PALOMINO et al., 2002).

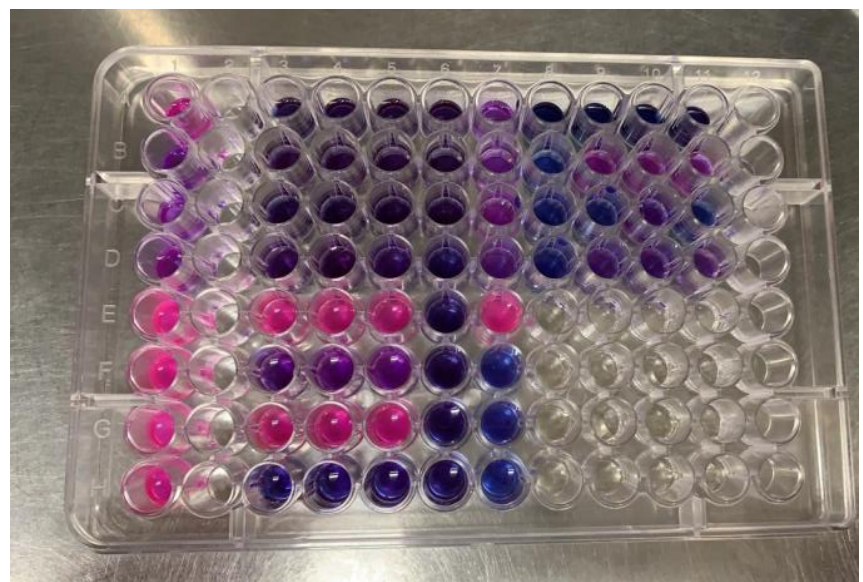

Figura 4 - Avaliação de viabilidade das bactérias utilizando o reagente resazurin, onde rosa indica a presença do microrganismo e azul, sua inibição.

\section{CONCLUSÕES}

0 método de aplicação de AgNPs de maior tamanho frente as cepas de S. aureus ATCC 6538 e B. subtilis ATCC 6633 testados apresentou inibição completa microbiana, o que mostra uma potencial aplicação das nanopartículas crescidas por semente, tendo uma alta anisotropia. A partícula de maior tamanho, utilizando $200 \mathrm{uL}$ da semente, teve uma maior eficácia quando comparada as outras utilizadas no percentual de inativação, que mostrou ser totalmente dependente do tamanho da partícula.

\section{REFERÊNCIAS}

NATIONAL COMMITTEE FOR CLINICAL LABORATORY STANDARDS (NCCLS). Methods for Dilution Antimicrobial Susceptibility Tests for Bacteria That Grow Aerobically; Approved Standard-Sixth Edition. NCCLS document M7-A6 (ISBN 1-56238-486-4). NCCLS, 940 West Valley Road, Suite 1400, Wayne, Pennsylvania 19087-1898 USA, 2003.

RUPARELIA, J. P.; CHATTERJEE, A. K.; DUTTAGUPTA, S. P.; MUKHERJI, S. Strain specificity in antimicrobial activity of silver and copper nanoparticles. Acta Biomaterialia, 4(3), 707-716, 2008. KIM, J. S.; KUK, E.; YU, K. N.; KIM, J.-H.; PARK, S. J.; LEE, H. J.; $\mathrm{CHO}$, M.-H. Antimicrobial effects of silver nanoparticles. Nanomedicine: Nanotechnology, Biology and Medicine, 3(1), 95101, 2007.

RAI, M;, YADAV, A.; \& GADE, A.. Silver nanoparticles as a new generation of antimicrobials. Biotechnology Advances, 27(1), 7683, 2009.

AZAM, A.; AHMED, A. S.; OVES, M.; KHAN, S. M.; HABIB, S. S.; MEMIC, A. Antimicrobial activity of metal oxide nanoparticles against Gram-positive and Gram-negative bacteria: a comparative study. International Journal of Nanomedicine, 6003, 2012.

AHERNE, D.; LEDWITH, D. M.; GARA, M.; KELLY, J. M. Optical Properties and Growth Aspects of Silver Nanoprisms Produced by a Highly Reproducible and Rapid Synthesis at Room Temperature. Advanced Functional Materials, v. 18, p 2005-2016, 2008.

SAADE, J. Síntese/Fabricação e caracterização de micro e nanoestruturas para aplicação na fotônica e plasmônica. $134 \mathrm{f}$. Dissertação (Doutorado), Centro De Ciências Exatas e da Natureza, Universidade Federal de Pernambuco, Recife, 2013.
DONG VAN, P.; HA, C. H.; BINH, L. T.; KASBOHM, J. Chemical synthesis and antibacterial activity of novel-shaped silver nanoparticles. International Nano Letters, 2(1), 2012.

PAL, S.; TAK, Y. K.; SONG, J. M. Does the antibacterial activity of silver nanoparticles depend on the shape of the nanoparticle? A study of the Gram-negative bacterium Escherichia coli. Applied and Environmental Microbiology, vol. 73,6 ,1712-20, 2007.

MORONES, J. R.; ELECHIGUERRA, J. L.; CAMACHO, A.; HOLT, K.; KOURI, J. B.; RAMÍREZ, J. T.; \& YACAMAN, M. J. The bactericidal effect of silver nanoparticles. Nanotechnology, 16(10), 2346-2353, 2005. 